\title{
Mobile Devices to Bridge the Gap in VET: Ease of Use and Usefulness as Indicators for Their Acceptance.
}

\author{
Elisa Motta ${ }^{1}$, Alberto Cattaneo ${ }^{1} \&$ Jean-Luc Gurtner ${ }^{2}$ \\ ${ }^{1}$ Swiss Federal Institute for Vocational Education and Training, Switzerland \\ ${ }^{2}$ Department of Education, University of Fribourg, Switzerland \\ Correspondence: Elisa Motta, Swiss Federal Institute for Vocational Education and Training, via Besso 84, \\ CH-6900 Lugano, Switzerland.
}

Received: July 23, 2013 Accepted: August 8, 2013 Online Published: November 8, 2013

doi:10.11114/jets.v2i1.184

URL: http://dx.doi.org/10.11114/jets.v2i1.184

\begin{abstract}
In the dual-track Vocational Education and Training (VET) system, apprentices gain experiences in different learning locations (i.e. workplace and school) but the bridges between these experiences are difficult to construct. Mobile devices could help to promote connectivity across learning contexts, provided they are accepted by the various persons and institutions involved. Ease of use and usefulness, here interpreted as the main elements of usability in the large, are indicators of the acceptance of mobiles. We involved apprentices from three different professional fields - cooks, pastry cooks and car mechanics - and two different mobile devices - headband cameras and smartphones. These devices served to capture visual material on professional situations lived at the workplace. Different software applications were then used to allow such material to be brought to school and discussed with teachers and classmates or shared with supervisors at work. To evaluate the usability of such tools we used a five-section questionnaire mainly based on the TAM and UTATUT model, which had been adequately adapted to the peculiarity of the VET system. Results confirm the feasibility of the approach and the usability of both tools: no significant difference is shown, neither between the two devices in the same field, nor between the different professions with respect to the same device. These results underline the potential of mobile devices to foster connectivity between learning locations in VET.
\end{abstract}

Keywords: mobile devices, ease of use, usefulness, usability, acceptance, multiple learning contexts, vocational education and training

\section{Introduction}

Learning theories acknowledge more and more that learning no longer occurs in a specific and unique context, such as a school, but in various locations (Engeström, Engeström, \& Kärkkäinen, 1995; Eraut, 2004; Resnick, 1987; Lave \& Wenger, 1991). In other words, learning often results from the integration of experiences made separately in diverse contexts or transferred from one context to another. However, as most studies on transfer have shown, overcoming the boundaries and passing knowledge from one context to another is a difficult process: what is learned remains often encapsulated in its original context and is seldom transferred to the other context (Renkl, Mandl, \& Gruber, 1996). The study presented in the current paper is part of a larger project (Dual-T; Note 1) whose aim is to connect the diverse learning locations within the Vocational Education and Training (VET) system, which otherwise can remain "parallel" and lack interaction, through the use of technologies; thus promoting the possibility of a boundary crossing, in particular between the two main learning locations where apprentices are daily involved: the school and the workplace. Within the project, various scenarios and tools have been developed, within which technologies serve as a means to: (1) capture meaningful professional situations at the workplace, (2) exploit this material in the classroom by developing learning activities which promote reflection on these experiences, and finally (3) validate back at the workplace the knowledge which has been elaborated at school during the exploitation phase (Cattaneo et al., 2013). The potential of mobile devices to serve as bridge builders is important and appealing. Although very useful in everyday life, it is not clear yet whether such devices (in the present study we will consider headband cameras and smartphones) are usable in a professional situation and can be accepted at the workplace as effective tools 
for learning, and whether the capture of real professional experiences and their later use at school represent for the various stakeholders useful ways to favor apprentices' professional knowledge development.

In the current paper we focus on exploring the perception of the ease of use, the usefulness and the acceptance by apprentices of such devices as learning tools.

\subsection{Vocational Training in Switzerland}

The Swiss education system is structured so that students completing the compulsory lower-secondary school cycle can select between two types of upper-secondary schools: selective schools, which prepare students for the Academic Baccalaureate; and vocational schools, which prepare students for the Federal VET Certificate or for the Vocational Baccalaureate. Roughly two-thirds $(65 \%)$ of the young people coming out of lower-secondary school enroll in a VET program, although a recent tendency shows a decrease in enrolments for the classic combined school/work-based VET program ("dual" system) and an increase in the number of young people staying in general education. Anyway, from a mere quantitative point of view, the VET system involves about $42 \%$ (OFS, 2012) of the population between 25 and 64 years old confirming itself as a tradition which characterizes the Swiss educational culture. The aim of vocational schools is, as made explicit in the 2002 Vocational and Professional Education and Training Act (VPETA), to create a professional training system that allows individuals to develop personally and professionally and to integrate into society, in particular in the employment sector, by making them capable and available to be professionally flexible and to remain in the employment sector (VPETA, Art. 3).

In order to fulfill these objectives, both professional and sociocultural, the training curricula have to be structured around the existence of different training agencies and on their interrelationship. That is why in Switzerland - similar to what happens in Germany and Austria - such paths are based on the so-called "dual" system, primarily organized in constant alternations between a work-based segment and a school-based segment. Concretely, this means that apprentices spend three to four days a week - depending on the profession - in a company, with which they have signed a regular contract and get paid, and the rest of the week at school where they are exposed to general subject matters (such as language or civics) and to more theoretical aspects linked to the professional sector in which they are engaged.

\subsection{When Learning Means Connecting Experiences from Multiple Locations: can mobile devices be a solution?}

In such a system, the process towards collaboration among learning locations really needs to be fostered, developed and better consolidated between what apprentices do in practice (workplace) and what they learn at school. Living heterogeneous experiences in each specific professional context, apprentices often perceive a gap between the locations instead of homogeneous training (Eteläpelto, 2008; Filliettaz et al, 2008; Taylor \& Freeman, 2011). In other words, this non-perfect link between the workplace and the school represents an opportunity and a source of problems at the same time: by splitting opportunities for learning over two main locations (i.e. workplace and school), the dual-track VET system implies that learning emerges from the interaction of multiple contexts (Gurtner et al., 2001; Horn et al., 2008). Being able to aggregate information and experiences gathered in two different contexts into a coherent body of knowledge seems to be a prerequisite for appropriate learning in such conditions. Because this connection between experiences and information is neither obvious nor spontaneous, we need to foster it through a specific learning environment design that is able to exploit the effects that the context has on the learners' motivation (Volet \& Järvelä, 2001), in line with Guile and Griffiths (2001), Tynjälä (2008) or Ludvingsen et al. (2011). In this framework, mobile learning seems to offer interesting opportunities for learning across contexts. In fact, in mobile learning literature, the role of the context is seen as fundamental: it features a dynamic entity constructed by the interactions between learners and their environment and not a mere container (Sharples et al., 2005, 2007). This is particularly true in an age, often called the Mobile Age, where - independently from the specificities of VET on which we have already focused learning no longer seems to be grounded in a fixed location or time, but as flowing across locations (Sharples et al., 2008; Sharples, 2009). But Mobile learning is 'not simply a variant of e-learning enacted with portable devices, nor an extension of classroom learning in less formal settings' (Sharples, 2009, p. 18): it gives the chance to create new contexts for learning, promoting interactions among people, technologies and settings, which is exactly what is needed to promote connectivity.

The presence of multiple learning locations also prompts reflection on the assumption that learners are continually on the move (Sharples et al., 2008); this means that they learn across two contexts using three types of move. First, they learn across physical spaces, picking experiences of different kinds (formal, informal, non-formal and practical) from several locations and elaborating them in other contexts. Second, they learn across time, through ideas and stimuli from past experiences considered useful for a lifetime of learning. 
Moreover, the learners make three kinds of move: (a) across topics, as they manage not only a personal and individual learning project, but also multiple and articulated curricula; (b) across technologies, that means they move in and out of engagement with technologies; and finally (c) across social spaces, where learners perform within various social groups, including encounters in workplaces or the classroom (Sharples et al., 2007). Differently said, according to El-Hussein and Cronje (2010), mobile learning refers to at least three different interdependent dimensions: learners' mobility, learning and technology. This last dimension still merits some points of attention. Considering the technological aspect, two main advantages of mobile learning are usually highlighted in the literature: on one side mobile devices have a high potential to support non-formal and informal learning (Pachler, 2009) as well as workplace learning; on the other side, in the perspective of experiential learning approaches, mobile devices would support and provide different educational affordances (Kirschner, 2002) such as real-time information retrieval and rapid access for note- or photo-taking (Lai et al., 2007). Mobile technologies can then be designed to best support apprentices on the move, particularly when learning happens in multiple learning locations. They move with the learners, across learning contexts (space and time), establishing with them an "individual" relationship as well as a "social" one, as learning content becomes shared with other learners and people involved in the learning process. Among others, Passey (2010) proposes mobile technologies to be the tools to capture experiences in a specific and fitting place so that they can in particular be shared with others. According to the author, mobile devices can in fact be useful for learning by making two distinctive activities possible: (1) the capture of ideas or real examples where and when they are generated or observed; (2) the sharing of captured work items with more knowledgeable people, promoting conversation and discussion. Once more, given that the VET framework features the structural presence of multiple contexts, mobile devices can represent a possible solution to bridge those gaps existing among the learning locations and can contribute to connect experiences lived in different locations. In our study, mobile devices allow apprentices to capture experiences in the place (the workplace) where the professional procedures really take place in order to reuse them in another learning location (the school).

Anyway, speaking about the "social" potentialities of mobile devices, there is still an additional step to make. Sharples et al. (2008) suggest that we should consider conversation to be an essential construct for understanding how mobile learning can be integrated with conventional education. The technology may enrich the environment in which conversation takes place because it can provide new tools and devices to collect data, to build and test models. It also provides new shared conversational learning spaces, which can be used not only for single learners but also for learning groups and communities (Sharples et al., 2007, 2008). The added value of portable devices is that they give apprentices the chance to collect and exploit material which becomes a further object of conversation. According to the definition of Sharples et al., this means that the apprentice can exploit the materials collected on the move (at the workplace especially) in a conversation process: (1) with herself/himself, for reflecting on her/his professional practices and mastery acquirement; (2) with peers and teachers at school, in various learning activities built around authentic professional situations; and (3) with supervisors and colleagues at the workplace, whom she/he can confront and with whom she can monitor her/his learning progress. In this way, mobile devices can act as real tools for thinking, helping apprentices to bring to school what they usually live outside (e.g. the workplace) where they spend the rest of their learning time, and vice versa, to bring back to the workplace the results of what has been exploited at school. In this way we support a VET-specific and sense-making use of mobile devices, embracing an approach proposed by Sharples et al., who define mobile learning 'as the process of coming to know through conversations across multiple contexts amongst people and personal interactive technologies' (Sharples et al., 2007, p. 225).

\subsection{Usability ... in the Large: the starting point to perform evaluation}

Implementing mobile technology in learning contexts requires us to reflect on how to approach the evaluation for the stakeholders involved in the process. Sharples (2009, p. 22) suggests three main aspects in order to perform such an evaluation: '1. usability (will it work?), (2) effectiveness (is it enhancing learning?) and 3. satisfaction (is it liked?)'. In the present paper our attention is mainly focused on the first of these three elements, which is the inescapable and preliminary condition to the other two aspects.

\subsubsection{Usability and Acceptance: definitions and interactions between the two concepts}

Strong links exist between the concept of usability and that of acceptance. As a starting point, we can consider: (1) the reasonable assumption that usability is 'a prerequisite of acceptance' (Holden \& Rada, 2011, p. 343) and (2) the fact that usability factors will become progressively dominant in the processes of acceptance made by users (Shackel, 1991, 1999). In other words, if a technology is not considered highly usable, it is unlikely that it will be accepted by the users; user acceptance is very important as it represents one of the crucial factors for the diffusions of technologies, although many technologies perceived as usable were never accepted by the users (Dillon, 2001). 
Given these assumptions, two main questions arise for our discussion: (1) how to define usability? and (2) how is usability related to acceptance?

Concerning the first question, the definition of usability is neither unique nor clear in the literature. In ISO 9241-11 (Ergonomic Requirements for Office Work with Visual Display Terminals; ISO, 1996), for instance, usability is approached in terms of: (1) efficiency, resources expended in relation to the accuracy and completeness with which users achieve goals; (2) effectiveness, the accuracy and completeness with which users achieve specified tasks; and (3) satisfaction, a subjective measure concerning the comfort and acceptability of use by end users. Given that the definition by ISO 9241-11 has become the standard within the "usability" community, the model introduced by Nielsen (1993) has been widely adopted. He proposes to explain usability in terms of the overall acceptability of a system through a model focused on its social and practical acceptability; the elements to be considered in this respect are four: (1) efficiency, referring to expert users only; (2) learnability, which is also directly related to efficiency; (3) memorability, mainly related to casual users; and (4) errors, which deals with those errors not covered by efficiency and which have more catastrophic results. Later on, Dix et al. (1998) propose a model in which usability is based on three main components: learnability, flexibility and robustness; they specify that these concepts are on the same abstraction level and they focus more on the concrete elements that influence usability.

This first and brief analysis of the concept of usability already reveals a strong overlap with the concept of acceptance. Given the fact that usability emerges as a strong reference point, it is crucial to understand how it can be operationalised. With this respect, it can be very useful to look at Hartson, who suggests that one should evolve towards the concept of usability in the large, defined as 'ease of use plus usefulness' (Hartson, 1998, p. 103). Ease of use is an important aspect to consider because a tool or an application 'perceived to be easier to use than another is more likely to be accepted by user' (Davis, 1989, p. 320). It includes such measurable attributes some of which are already implicitly present in the previously cited definition - as learnability, speed of user task performance, user error rates, and subjective user satisfaction, as Hix and Hartson (1993) or Shneiderman (1992) propose. But, according to Hartson, ease of use is not enough because it does not take into account the functionality that supports users' needs. So, in this framework, usefulness plays a crucial role: it is 'perhaps the primary usability factor, the factor that provides immediate access and affordance to the functionality without getting in the way' (Hartson, 1998, p. 103). This is why, as already mentioned, in the present study we will focus both on the ease of use and the usefulness, which can be also approached as indicators of acceptance (§1.3.2).

According to this well-established and expanded meaning, usability is then the preliminary condition which the actors involved (apprentices first, in the present case) need to perceive in order to later use technology tools in their contexts. In the current paper, we will apply this concept to mobile devices. Mobile usability can be considered both an emerging and a new and specific branch within the more general field of usability, where it is important to really consider and understand all the factors that determine the way people operate (Kukulska-Hulme, 2007). We need to take into account the peculiarity of the mobile devices we chose to implement in the VET context and take into consideration that they have the potential to introduce innovation, especially in the VET system in which this study takes place. In order to promote a concrete and real implementation of a technology, we need then to define: (1) whether the use of the devices is feasible in the specific learning locations and (2) to verify whether and how the portable technologies are fitting tools to capture experiences at the workplace. In particular we considered here two different kinds of devices: smartphones and headband wearable cameras. These two devices have been used to capture in a visual form meaningful traces of professional situations experienced at the workplace. Two corresponding tools were then included in the study: an online environment (called Mobile and Online Tool - MOT) to further exploit the raw materials (pictures) captured through the smartphone and a hypervideo interface for exploiting the videos collected through the headband camera. We give further details on the specific procedure in the corresponding section (\$2.1).

\subsubsection{How to Measure Usability in the Large: ease of use and usefulness as indicators of acceptance}

Taking into account, first, the concept of usability in the large and its main components (ease of use and usefulness) and, second, the strong interaction, as shown before, between the concepts of usability and acceptance, we could not avoid revealing a very well-grounded and diffused model called Technology Acceptance Model (TAM) by Davis (1989), in which acceptance is considered to be composed of exactly the two same main components: ease of use and usefulness.

Within this perspective, Davis (1989) developed and validated a scale focused on the two theoretical constructs: perceived ease of use and perceived usefulness. Perceived ease of use refers to 'the degree to which a person believes that using a particular system would be free of effort' (Davis, 1989, p. 320). The idea is that a tool which 
is perceived as easier to use than another one has more chance to be accepted by users. Perceived usefulness is defined as 'the degree to which a person believes that using a particular system would enhance his or her job performance' (Davis, 1989, p. 320). Davis's research shows that ease of use and usefulness measures can explain approximately $50 \%$ of the variance in acceptance. This first model was then further developed (Venkatesh \& Davis, 2000) with the specific aim of including complementary aspects and variables related to the context of use because technologies are not isolated, but embedded in working practices, in specific contexts and in networks of social relationships. This effort finally brought a further evolution of the TAM into the Unified Theory of Acceptance and Use of Technology model (UTAUT; Venkatesh et al., 2003). This new model raised the percentage of the explained variance in usage intention to $70 \%$. Four key constructs play a significant role in this model as directly influencing and determining the user's acceptance and usage behavior: (1) performance expectancy (individual beliefs to attain gains in job performance helped by using the system); (2) effort expectancy (very close to the Ease Of Use scale in TAM model, it is the degree of ease of use of the system); (3) social influence (which describes individual perception about others belief that she/he should use the system); and (4) facilitating conditions (individual belief to consider organizational and technical infrastructures as supports in using the system). But the model also includes moderating variables, such as gender, age, experience, and voluntariness of use, which are posited to mediate the impact of the four key constructs as well as other aspects such as attitudes toward the use of technology, behavioral intentions, self-efficacy or anxiety. Attitude toward using technology is defined as the individual's overall affective reaction to using a system, and behavioral intentions are defined as the behavior adopted in the subsequent time period (Venkatesh et al., 2003). Self-efficacy and anxiety have been modeled as indirect determinants of use intentions, which are fully mediated by perceived ease of use.

In the present study we chose to combine the two instruments (TAM and UTAUT) in order to gain evidence on the two main fundamental determinants of users' acceptance (perceived ease of use and perceived usefulness) as well as on the main contextual elements influencing acceptance.

\section{Method}

\subsection{Research Questions, Procedures and Samples}

The current study recognizes an added value of mobile devices as a means to capture real professional experiences from the workplace for later use at school. Within the general framework of the Dual-T project, learning activities based on such captured material were organized and delivered in the classroom in order to favor professional knowledge development. Considering usability of mobile devices to be the first, preliminary and inescapable learning process step, the present study deals with the following two research questions:

a) Are mobile technologies easy to use at the workplace?

b) Are mobile technologies perceived to be useful as tools to aid reflection at school on workplace experiences and to foster the learning of professional knowledge?

In our study we involved three groups of apprentices: (1) car mechanics, (2) pastry cooks, and (3) cooks.

The headband users (apprentice car mechanics and cooks) wore the camera, placed on their own forehead thanks to a fitting band, in order to record professional procedures during their daily activities at the workplace (see Figure 1). These devices did not hinder the progress of their usual job, thanks to their small dimension and to their lightness, letting their hands free without obstructing their body movements.
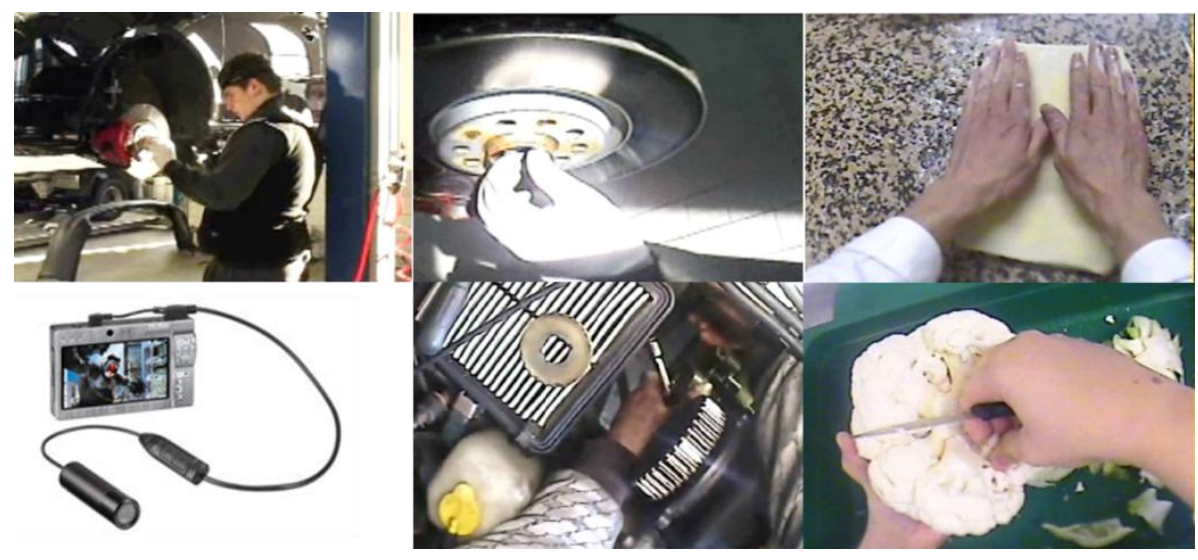

Figure 1. Use of headbands among car mechanics and cooks 
The headbands were at their disposal, in the garages or the kitchens, for 1 to 4 weeks, during which they were requested to record some videotapes of their professional activities. Choosing which procedure to record could: (1) be left to the apprentices' own discretion; (2) follow a recommendation from the apprentice's boss; and (3) be suggested by the professional subject teacher, who could ask to collect some procedures particularly relevant to the curriculum (e.g. the adjustment of valves, the timing chain phasing, the overhauling of the cooling system, in the case of car mechanics). The videos were brought back to the teacher who selected and edited the most meaningful sequences (according to him or her) in a brief clip (3 to 5 minutes, each one) for each topic. The teacher then worked on the clips in order to realize several hypervideos (Chambel et al., 2004, 2006; Zahn et al., 2004). Each video was then organized in chapters, and enriched with additional learning materials (texts, pictures, schemes and audios) and tasks (check and revision questions, exercises) to be easily approached through suitable markers (hotspots). These videos were then integrated into a didactical scenario around which the teacher orchestrated a discussion with the whole class.

Each smartphone user (apprentice pastry cooks and cooks) received one personal device to be used at the workplace. They also were instructed on the use of a specific application to index pictures (PixelPipe), and shown how to select some of these pictures to build their own recipe book and to keep a learning journal (Mauroux et al., 2013). We refer to this complete system as the MOT. Using a pre-structured scheme prepared in collaboration with the teacher and professionals of the field (see left side of Figure 2), apprentices were asked to write and illustrate recipes (by writing text within several fields - e.g. ingredients, temperature, main steps of the recipe, etc. - and attaching pictures taken at the workplace, in order to better describe and detail the procedures). For each recipe they could develop, in a linked page, their reflections on the action performed, the so-called "learning journal" (see right side of Figure 2; Note 2). Apprentices' reflections were guided with three prompts, derived from the work of Kicken et al. (2009). They also had to regularly self-evaluate their global level of mastery of each recipe and to write a summary featuring the crucial things they need to remember when they do the recipe. A space is left in the journal page for a comment or an evaluation by the supervisor. A home page allows the apprentices to keep an overview on the development of their own professional competences.

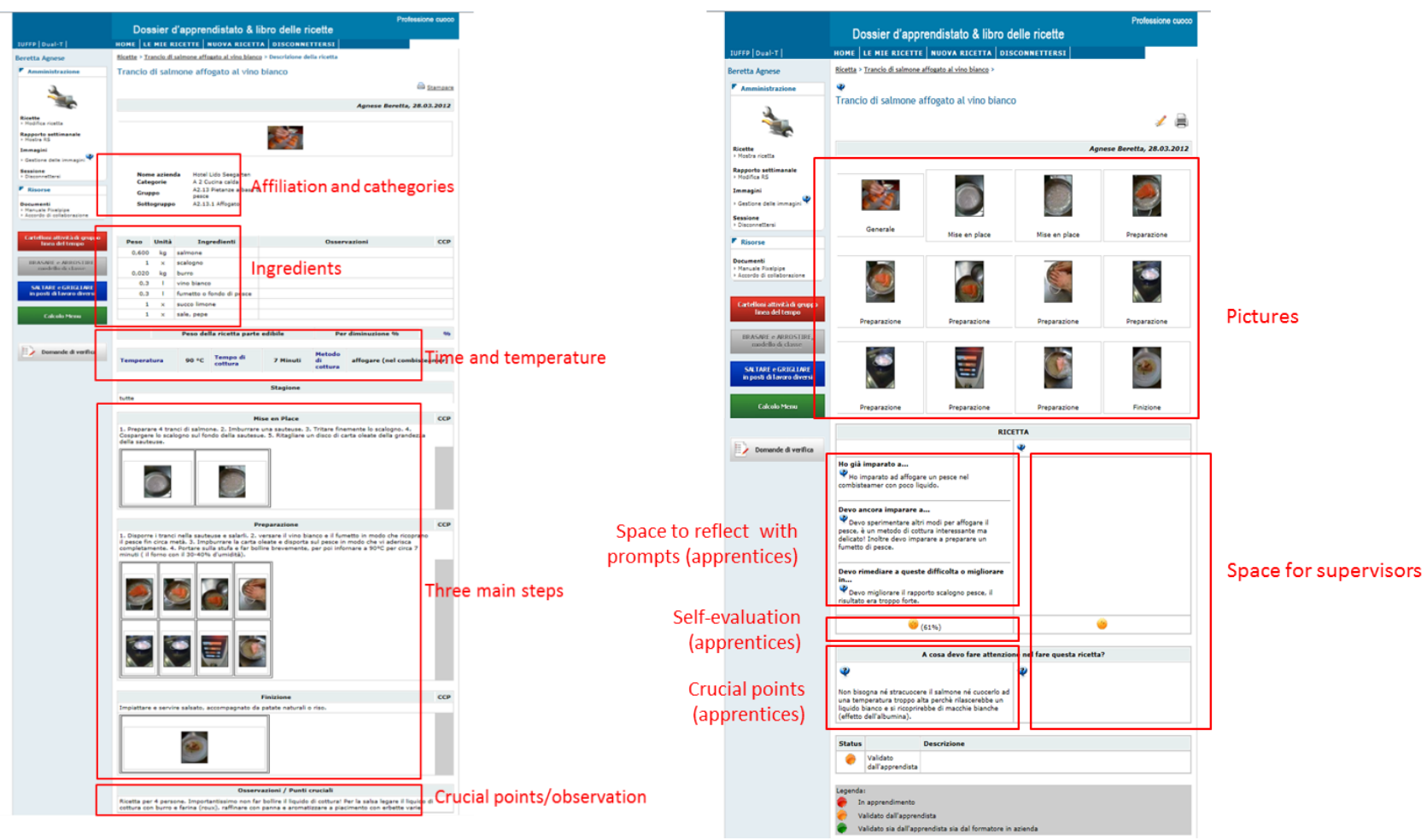

Figure 2. Recipe and learning journal in the MOT

Summarizing, the present study involves apprentices from three professions who experienced the use of mobile: (1) the headband camera (and the related videos) for car mechanics and cooks, and (2) the smartphone (and related MOT) by cooks and pastry cooks. In depth, we aim at investigating the usability of both devices and related tools, focusing on how the users perceive the ease of use and also the usefulness of the mobile system 
after having had a chance to really experiment with it as part of their own training.

For the experiments with headband cameras, we involved 19 apprentice car mechanics (in their second year of training) and 8 cooks (in their first year) from two different Vocational Schools (respectively Biasca and Trevano); they were given a headband camera to be used for 1 to 4 weeks each, in turn. Concerning the smartphone, 15 apprentice pastry cooks (a whole second-year class) from the Vocational School of Fribourg as well as apprentice 22 cooks (a whole first year class) from the Vocational Centre of Trevano took part in the experiment. An overall view of the sample is reported in Table 1.

Table 1. Distribution of the samples according to professions and mobile devices used

\begin{tabular}{lcc}
\hline & Smartphone users & Headband users \\
\hline Pastry cooks & 15 & - \\
Cooks & 22 & 8 \\
Car mechanics & - & 19 \\
\hline
\end{tabular}

During implementation of the smartphone (from January to July 2011), the class of cooks collected 349 recipes, even though with a considerable scatter $(\mathrm{M}=15.9, \mathrm{SD}=17.8)$, and uploaded 1688 pictures from their own experiences of which 915 were attached to their respective recipes. The pastry cooks collected a total of 534 recipes (between October 2010 and July 2011), also with a considerable scatter ( $M=31.40, S D=31.80)$.

Among those who used the headband cameras, the apprentice car mechanics collected a total of 110 raw videos concerning 34 different professional procedures (from September 2009 to July 2011) for a total of 17 hours and 42 minutes. The cooks collected 146 raw sequences related to 18 different professional procedures (from January to July 2011) for a total of 23 hours and 53 minutes.

\subsection{Data Collection and Measures}

In order to answer our research questions, we submitted to all the participants a five-section questionnaire, aiming at exploring: (1) the overall perceived ease of use, (2) the learnability, (3) the detailed perceived ease of use, (4) the usefulness of the devices, and finally (5) the usefulness of the tools (MOT and hypervideo).

The first section of the questionnaire focused on participants' overall perception of the ease of use of the two devices; apprentices were asked whether they found them really easy to use or not and whether they needed somebody to support them during the use of the device at the workplace. Questions here had to be answered by choosing only one among three options (Easy to use; Easy, but with support; Difficult to use).

In the second section, the users' point of view on the learnability of the device itself was collected in a dedicated section. Regarding the headband, we asked apprentices if they had faced difficulties to: (1) switch the device on and off; (2) record video; (3) frame the device in the right way; (4) wear the headband camera, including the "case" and the belt on the head; (5) charge it; and (6) if they had faced any other kind of difficulties. Concerning the smartphone, we asked information about the troubles they found in: (1) taking pictures using the camera fitting integrated in the device (a 3G iPhone model); (2) sending pictures through the fitting application; (3) accessing the picture store on the platform; (4) deleting pictures; (5) associating pictures and recipes; and finally (6) adding new recipes. One can notice that in this latter case we could not completely separate the use of the device from the use of the related tool because pictures taken are then uploaded in the dedicated environment. For this section, the apprentices had to select an option(s) from among the above cited options that corresponded to their experience.

In the third section, we submitted the six items on perceived ease of use of the TAM scale (on a 7-point Likert scale, from -3 , I don't agree at all, to +3 , I fully agree) to all the apprentices of the sample (car mechanics, cooks and pastry cooks).

In the fourth section, we submitted items on the overall usefulness of the devices. We chose the UTAUT model, in order to also include further contextual elements (Note 3). Also in this case the items were based on the same 7-point Likert scale. On the one hand, we mainly considered the items on the key constructs of the model with a direct effect on acceptance and use excluding the Effort expectancy dimension, which is already well considered in the TAM: performance expectancy, social influences and facilitating conditions. On the other hand, regarding the indirect constructs, we chose to use at least one item in order to guarantee overall coverage of the validated scale dimensions (see Table 2). In addition, a reliability analysis was conducted for the scales using Cronbach's Alpha: considering all the items of our questionnaire, we got a good degree of reliability $(\alpha=.785)$. 
Table 2. UTAUT items selected to build the fitting questionnaire

\begin{tabular}{|c|c|}
\hline Dimension & UTAUT items with explicit references \\
\hline Performance expectancy & I find this smartphone/headband useful in my job/for activities at school. \\
\hline \multicolumn{2}{|l|}{1 out of 4 items } \\
\hline Attitudes towards using technologies & I like working with the smartphone/headband. \\
\hline \multirow[t]{3}{*}{4 out of 4 items } & Using the smartphone/headband is a good idea. \\
\hline & Using the smartphone/headband is fun. \\
\hline & The smartphone/headband makes work more interesting. \\
\hline Social influence & People who influence my behavior (chief, colleagues, and teachers) think that I \\
\hline \multirow[t]{4}{*}{3 out of 4 items } & should use the smartphone/headband. \\
\hline & My boss encouraged me to use the smartphone/headband at the workplace/My \\
\hline & boss has been helpful in the use of the system. \\
\hline & My colleagues helped me to use the smartphone/headband. \\
\hline Facilitating conditions & Smartphone/headband use obstructed my development at the workplace. \\
\hline 4 out of 4 items & Smartphone/headband use is compatible with daily life aspect of the job. \\
\hline & I can use the smartphone/headband if I have an assistance/guide at my disposal. \\
\hline & I can use the smartphone/headband if someone explains to me how to use it. \\
\hline Self-efficacy & If there was no one around to tell me what to do as I go I could use the \\
\hline 1 out of 4 items & smartphone/headband. \\
\hline Anxiety & I feel apprehensive about using the smartphone/headband. \\
\hline
\end{tabular}

Behavioral intention to use the system I intend to use the smartphone/headband (if I have it at my disposal).

1 out of 4 items

In the last section, finally, we submitted specific items aimed at investigating whether such a complex tool could be useful in multiple contexts (school, job or both). In detail, concerning the MOT, we considered the apprentices' point of view on: (1) the perceived ease of use, by TAM (six items); (2) the choice of terms to describe it, through a set of eight words (see the Results section); (3) the perceived usefulness for learning. This was done using an ad hoc corpus of items aimed at a better understanding of how apprentices perceived the use of the MOT for learning taking into account the learning locations where they are integrated. Examples of items related to the MOT were: "The system helps me to remember what I learned at the workplace", "The system helps me to identify the links between what I have learnt at school and what I have learnt at the workplace", "The system helps me to make links among different experiences lived at the workplace". For this additional scale we got a very good degree of reliability $(\alpha=.951)$. In the case of headband cameras, in order to describe the usefulness of the hypervideo tool produced by the teachers to be used in class, we submitted a set of seven specific items, which also proved to have a good degree of reliability $(\alpha=860)$. Examples of items related to the hypervideo were: "I find it useful for the school", "I find it useful for the workplace", and "It allows me to share what I usually do at the workplace with my peers".

\section{Results}

\subsection{Overall Ease of Use}

Most apprentices ( at least easily usable with somebody's support ( apprentice (within the cook group) considered the headband device difficult to use.

Table 3. Distribution of participants' answers to the overall ease of use questions

\begin{tabular}{|c|c|c|c|c|c|c|c|c|c|c|c|c|}
\hline & \multicolumn{6}{|c|}{ Smartphone } & \multicolumn{6}{|c|}{ Headband } \\
\hline & \multicolumn{2}{|c|}{$\begin{array}{l}\text { Tot } \\
(37)\end{array}$} & \multicolumn{2}{|c|}{$\begin{array}{c}\text { Cooks } \\
(22) \\
\end{array}$} & \multicolumn{2}{|c|}{$\begin{array}{c}\text { Pastry cooks } \\
(15)\end{array}$} & \multicolumn{2}{|c|}{$\begin{array}{l}\text { Tot } \\
(27) \\
\end{array}$} & \multicolumn{2}{|c|}{ Car mechanics (19) } & \multicolumn{2}{|c|}{$\begin{array}{c}\text { Cooks } \\
(8)\end{array}$} \\
\hline & $\mathrm{n}$ & $\%$ & $\mathrm{n}$ & $\%$ & $\mathrm{n}$ & $\%$ & $\mathrm{n}$ & $\%$ & $\mathrm{n}$ & $\%$ & $\mathrm{n}$ & $\%$ \\
\hline Easy to use & 28 & 75.7 & 17 & 77.3 & 11 & 73.3 & 16 & 59.3 & 13 & 68.4 & 3 & 37.5 \\
\hline Easy, but with support & 9 & 24.3 & 5 & 22.7 & 4 & 26.7 & 10 & 37.0 & 6 & 31.6 & 4 & 50.0 \\
\hline Difficult to use & 0 & 0.0 & 0 & 0 & 0 & 0 & 1 & 3.7 & 0 & 0 & 1 & 12.5 \\
\hline
\end{tabular}




\subsection{Learnability of Mobile Devices}

Results regarding the specific operations to be performed, and the likelihood of experiencing difficulties doing them, are given in Table 4. It can be seen that apprentices seldom mentioned difficulties. Concerning the smartphone and the MOT, the most often admitted difficulty concerned associating pictures with recipes (27.0\% and even $40.9 \%$ of the cooks mentioned it) and uploading the pictures to the platform (18.9\% and $33.3 \%$ mentions among pastry cooks. As regards the headband cameras, almost half of the car mechanics mentioned having experienced no difficulty at all $(47.4 \%)$ but none of the cooks shared this impression. Both professions faced some trouble in framing the camera (50.0\% of cooks and $42.1 \%$ of car mechanics), a task which requests accuracy and precision at the beginning of the recording, and to a lesser extent, in charging the system (18.5\% and $25.0 \%$ cooks apprentices).

Table 4. Number and percentages of participants mentioning having had difficulties with given features of the tools

\begin{tabular}{|c|c|c|c|c|c|c|c|c|c|c|c|c|c|}
\hline \multirow[t]{2}{*}{ Smartphone } & \multicolumn{2}{|c|}{ Tot } & \multicolumn{2}{|c|}{ Cooks } & \multicolumn{2}{|c|}{$\begin{array}{l}\text { Pastry } \\
\text { cooks }\end{array}$} & \multirow[t]{2}{*}{ Headband } & \multicolumn{2}{|c|}{ Tot } & \multicolumn{2}{|c|}{ Cooks } & \multicolumn{2}{|c|}{$\begin{array}{c}\text { Car } \\
\text { mechanics }\end{array}$} \\
\hline & $\mathrm{n}$ & $\%$ & $\mathrm{n}$ & $\%$ & $\mathrm{n}$ & $\%$ & & $\mathrm{n}$ & $\%$ & $\mathrm{n}$ & $\%$ & $\mathrm{n}$ & $\%$ \\
\hline Taking pictures & 1 & 2.7 & 0 & 0.0 & 1 & 6.7 & $\begin{array}{l}\text { Switching } \\
\text { on-off }\end{array}$ & 1 & 3.7 & 1 & 12.5 & 0 & 0.0 \\
\hline Uploading pictures & 7 & 18.9 & 2 & 9.1 & 5 & 33.3 & Recording & 3 & 11.1 & 2 & 25.0 & 1 & 5.3 \\
\hline Accessing pictures online & 6 & 16.2 & 5 & 22.7 & 1 & 6.7 & Framing & 12 & 44.4 & 4 & 50.0 & 8 & 42.1 \\
\hline Deleting pictures & 4 & 10.8 & 3 & 13.6 & 1 & 6.7 & Wearing & 3 & 11.1 & 1 & 12.5 & 2 & 10.5 \\
\hline Associating pictures-recipes & 10 & 27.0 & 9 & 40.9 & 1 & 6.7 & Charging & 5 & 18.5 & 2 & 25.0 & 3 & 15.8 \\
\hline Adding new recipes & 2 & 5.4 & 2 & 9.1 & 0 & 0.0 & No difficulties & 9 & 33.3 & 0 & 0.0 & 9 & 47.4 \\
\hline
\end{tabular}

\subsection{Perceived Ease of Use of the Two Mobile Devices}

In order to evaluate the perceived ease of use, we submitted the whole TAM scale (six items, seven-point Likert-scale, from -3 to +3 ). Taking into account all the data collected, both headband cameras and smartphones seem to be well considered by apprentices. Comparing car mechanics and cooks headband users, no significant differences emerge and their evaluations are quite high $\left(\mathrm{M}_{\text {car mechanics }}=2.02, \mathrm{SD}_{\text {car mechanics }}=.68 ; \mathrm{M}_{\text {cooks }}=2.15\right.$, $\mathrm{SD}_{\text {cooks }}=.60$ ). If we compare the cooks and pastry cooks smartphone users, the scores are still quite high, but lower than those of the headband users $\left(\mathrm{M}_{\text {cooks }}=1.76, \mathrm{SD}_{\text {cooks }}=1.38 ; \mathrm{M}_{\text {pastry cooks }}=1.78, \mathrm{SD}_{\text {pastry cooks }}=1.20\right)$. Considering all the cooks, as you can see, there are no significant differences between smartphone and headband users $\left(\mathrm{M}_{\text {cooks smartphone }}=1.76, \mathrm{SD}_{\text {cooks smartphone }}=1.38 ; \mathrm{M}_{\text {cooks headband }}=2.15, \mathrm{SD}_{\text {cooks headband }}=.60\right)$.

In sum, no significant differences appear neither between the two devices within a same profession (headband $v s$ smartphone cook users), nor between different professions with respect to the same device (car mechanics $v s$ cooks for headbands; cooks vs pastry cooks for smartphones), nor between all the headband users (car mechanics and cooks) and the smartphone users (cooks and pastry cooks).

\subsection{Usefulness of Mobile Devices}

Data collected through the selection of UTAUT items (Table 2) show significant differences among the headband users (cooks=8; car mechanics=19) concerning two main dimensions, where the cooks had more positive perceptions than the car mechanics: performance expectancy $(\mathrm{T}$ test: $\mathrm{t}(25)=-3.60, \mathrm{p}<.05, \mathrm{r}=0.58)$ and attitude towards technology $(\mathrm{T}$ test: $\mathrm{t}(25)=-3.26, p<0.05, \mathrm{r}=.55)$. No significant differences appeared on any of the remaining five dimensions considered by the model. At a more descriptive level, we can notice (see Table 5) that the means concerning the apprentice cooks are always slightly higher than those of the car mechanics. Among the smartphone users an analogous difference emerges between professions. Again, the cooks $(\mathrm{M}=2.00 ; \mathrm{SD}=1.57)$ share a significantly higher perception concerning performance expectancy (T test: $\mathrm{t}(32)=2.97, p<0.05, \mathrm{r}=.46$ ) than do the pastry cooks $(\mathrm{M}=.25 ; \mathrm{SD}=1.76)$, the same dimension where the cooks already surpassed the car mechanics when they were wearing a headband camera. No other dimension from the UTAUT model shows further significant differences among smartphone users. Results on the Anxiety dimension are also consistent with this view, as they confirm that using these devices at the workplace is not associated with an increase in anxiety; apprentice cooks even show a very low value on this dimension, although with an important scatter between them $(\mathrm{M}=-1.05 ; \mathrm{SD}=2.06)$. 
Table 5. Descriptive findings on UTAUT dimensions for headband and smartphone users

\begin{tabular}{|c|c|c|c|c|c|}
\hline UTAUT dimensions & & Profession & $\mathrm{n}$ & $\mathrm{M}$ & $\mathrm{SD}$ \\
\hline \multirow{4}{*}{ Performance expectancy } & \multirow{2}{*}{ Headband users } & Car mechanics & 19 & 1.37 & 1.74 \\
\hline & & Cooks & 8 & 2.88 & .35 \\
\hline & \multirow{2}{*}{ Smartphone users } & Cooks & 22 & 2.00 & 1.57 \\
\hline & & Pastry cooks & 12 & .25 & 1.76 \\
\hline \multirow{4}{*}{ Attitudes to technology } & \multirow{2}{*}{ Headband users } & Car mechanics & 19 & .18 & 1.56 \\
\hline & & Cooks & 8 & 2.06 & .68 \\
\hline & \multirow{2}{*}{ Smartphone users } & Cooks & 22 & .70 & 1.62 \\
\hline & & Pastry cooks & 15 & .20 & 1.61 \\
\hline \multirow{4}{*}{ Social influence } & \multirow{2}{*}{ Headband users } & Car mechanics & 19 & .75 & 1.25 \\
\hline & & Cooks & 8 & 1.17 & .91 \\
\hline & \multirow{2}{*}{ Smartphone users } & Cooks & 22 & .41 & 1.40 \\
\hline & & Pastry cooks & 15 & .089 & 1.64 \\
\hline \multirow{4}{*}{ Facilitating conditions } & \multirow{2}{*}{ Headband users } & Car mechanics & 19 & .17 & .95 \\
\hline & & Cooks & 8 & .59 & 1.08 \\
\hline & \multirow{2}{*}{ Smartphone users } & Cooks & 22 & -.23 & .96 \\
\hline & & Pastry cooks & 15 & -.13 & 1.12 \\
\hline \multirow{4}{*}{ Self-efficacy } & \multirow{2}{*}{ Headband users } & Car mechanics & 19 & 1.74 & 1.41 \\
\hline & & Cooks & 8 & 1.50 & .93 \\
\hline & \multirow{2}{*}{ Smartphone users } & Cooks & 22 & 1.27 & 1.64 \\
\hline & & Pastry cooks & 15 & .07 & 1.94 \\
\hline \multirow{4}{*}{ Anxiety } & \multirow{2}{*}{ Headband users } & Car mechanics & 19 & .68 & 2.11 \\
\hline & & Cooks & 8 & .38 & 2.26 \\
\hline & \multirow{2}{*}{ Smartphone users } & Cooks & 22 & -1.05 & 2.06 \\
\hline & & Pastry cooks & 15 & .47 & 2.64 \\
\hline \multirow{4}{*}{ Behavioral intention } & \multirow{2}{*}{ Headband users } & Car mechanics & 19 & 1.53 & 1.58 \\
\hline & & Cooks & 8 & 2.38 & 1.06 \\
\hline & \multirow[t]{2}{*}{ Smartphone users } & Cooks & 22 & 1.86 & 1.17 \\
\hline & & Pastry cooks & 15 & 1.27 & 2.12 \\
\hline
\end{tabular}

\subsection{Ease of Use and Usefulness of the Tools}

As already mentioned, for the smartphone users we duplicated the items of the TAM in order to also catch their perceptions of the MOT, the system with which they had to build their recipe book and their learning journal. Results show that apprentices rated the ease of use of MOT in a positive way, too, in both professions involved $\left(\mathrm{M}_{\text {cooks }}=1.51 ; \mathrm{SD}_{\text {cooks }}=1.18 ; \mathrm{M}_{\text {pastry cooks }}=1.32 \mathrm{SD}_{\text {pastry cooks }}=1.37\right)$, especially considering that values are quite scattered. No significant differences appeared between the two professions.

In addition, apprentices were asked to select within a list of eight adjectives all the ones that in their eyes best defined their experience with the MOT. As shown in Table 6, the most often chosen term in both the professions is "interesting" (cooks $=36.4 \%$; pastry cooks $=40.0 \%$ ). Among the terms with a rather negative meaning, the word "tiring" (cooks $=18.2 \%$; pastry cooks $=26.7 \%$ ) has the more consistent percentage in both professions.

Table 6. Words to define the MOT

\begin{tabular}{lllllllll}
\hline & Stressful & Distressing & Funny & Motivating & Repugnant & Tiring & Interesting & Other \\
\hline Cooks & $4.5 \%$ & $9.1 \%$ & $13.6 \%$ & $4.5 \%$ & $0.0 \%$ & $18.2 \%$ & $36.4 \%$ & $9.1 \%$ \\
Pastry cooks & $20.0 \%$ & $20.0 \%$ & $0.0 \%$ & $13.3 \%$ & $20.0 \%$ & $26.7 \%$ & $40.0 \%$ & $0.0 \%$ \\
\hline
\end{tabular}

Finally, as already mentioned, we measured the perceived usefulness of the tools.

Smartphone users. Concerning the MOT, we added a corpus of items, elaborated ad hoc, in order to deepen our understanding of how apprentices perceived the use of the MOT for learning. Overall results including the whole corpus showed no significant differences between cooks and pastry cooks $\left(\mathrm{M}_{\text {cooks }}=1.64, \mathrm{SD}_{\text {cooks }}=.95 ; \mathrm{M}_{\text {pastry }}\right.$ cooks $=.86, \mathrm{SD}_{\text {pastry cooks }}=1.43$ ): both professions consider the MOT useful (i.e. all the ratings being quite positive; see Table 7). Significant differences between cooks' and pastry cooks' appraisals appeared on two specific items: "The system helps me to decide the contents and my learning progress" and "the system helps me to recognize the links between what I have learnt at school and what I have learnt at the workplace" (respectively: T test: $\mathrm{t}(33)=2.34, p<0.05, \mathrm{r}=0.38$; $\mathrm{T}$ test: $\mathrm{t}(33)=2.62, p<0.05, \mathrm{r}=.42)$. In both cases, the cooks were more positive than 
the pastry cooks (respectively $\mathrm{M}_{\text {cooks }}=1.54$ and $\mathrm{M}_{\text {pastry cooks }}=.38$ for the first item and $\mathrm{M}_{\text {cooks }}=2.05$ and $\mathrm{M}_{\text {pastry }}$ cooks $=.69$ for the second). The cooks also expressed higher ratings than the pastry cooks in all but one of the other items, but the differences are not significant.

Table 7. Descriptive data on the usefulness of MOT, ad hoc scale

\begin{tabular}{|c|c|c|c|c|}
\hline The system helps me to... & Profession & $\mathrm{n}^{*}$ & M & SD \\
\hline \multirow{2}{*}{...capture and document experiences lived at the workplace. } & Cooks & 22 & 1.95 & .95 \\
\hline & Pastry cooks & 13 & 1.08 & 1.85 \\
\hline \multirow{2}{*}{...reflect on my learning process. } & Cooks & 22 & 1.60 & 1.10 \\
\hline & Pastry cooks & 12 & .92 & 2.19 \\
\hline \multirow{2}{*}{...remember what I learnt at the workplace. } & Cooks & 22 & 1.86 & 1.12 \\
\hline & Pastry cooks & 13 & .92 & 2.10 \\
\hline \multirow{2}{*}{...recognize and memorize my mistakes. } & Cooks & 22 & 1.45 & 1.47 \\
\hline & Pastry cooks & 13 & 1.08 & 1.55 \\
\hline \multirow{2}{*}{...understand what we have to pay attention to during a task. } & Cooks & 22 & 1.95 & 1.04 \\
\hline & Pastry cooks & 13 & 1.15 & 1.62 \\
\hline \multirow{2}{*}{...have an overall viewing concerning what we do. } & Cooks & 22 & 1.59 & 1.10 \\
\hline & Pastry cooks & 13 & .92 & 1.66 \\
\hline \multirow{2}{*}{...evaluate my training and progression state at the workplace. } & Cooks & 22 & 1.09 & 1.51 \\
\hline & Pastry cooks & 13 & 1.15 & 1.67 \\
\hline \multirow{2}{*}{$\ldots$ to decide the contents and my learning progress. } & Cooks & 22 & 1.54 & 1.40 \\
\hline & Pastry cooks & 13 & .38 & 1.44 \\
\hline \multirow{2}{*}{...learn from my mistakes and improve. } & Cooks & 22 & 1.64 & 1.33 \\
\hline & Pastry cooks & 13 & .69 & 1.89 \\
\hline \multirow{2}{*}{...make links among the different experiences lived at the workplace. } & Cooks & 22 & 1.36 & 1.36 \\
\hline & Pastry cooks & 13 & .61 & 1.61 \\
\hline \multirow{2}{*}{...understand the links among the different steps/phases of a recipe. } & Cooks & 22 & 1.64 & 1.25 \\
\hline & Pastry cooks & 13 & .77 & 1.70 \\
\hline \multirow{2}{*}{$\begin{array}{l}\text {...recognize the links between what I have learnt at school and what I have } \\
\text { learnt at the workplace. }\end{array}$} & Cooks & 22 & 2.05 & 1.05 \\
\hline & Pastry cooks & 13 & .69 & 2.02 \\
\hline
\end{tabular}

* Number differs because only valid cases are counted.

Headband users. We also submitted a set of items to the headband users in order to analyze how they judge the hypervideos elaborated by the teacher on the basis of videos recorded by apprentices at the workplace. A Mann-Whitney test indicated that overall the cooks' perception of the usefulness of the hypervideos was higher than that of the car mechanics $(U=7.000, p=0.000, \mathrm{r}=-.71)$. In other words, we could say that apprentice cooks see the potentiality of sharing experiences lived at the workplace with peers and teachers. In Table 8 we show the details concerning each item for both professions.

Table 8. Perceived usefulness of using hypervideos enriched by professional experience at school

\begin{tabular}{|c|c|c|c|c|}
\hline & \multicolumn{2}{|c|}{$\begin{array}{c}\text { Car mechanics* } \\
(16)\end{array}$} & \multicolumn{2}{|c|}{$\begin{array}{c}\text { Cooks* } \\
(8)\end{array}$} \\
\hline & M & SD & M & SD \\
\hline I like it & 1.25 & 1.34 & 2.75 & 0.46 \\
\hline I find it useful for the school & 1.37 & 1.41 & 2.62 & 0.52 \\
\hline I find it useful for the workplace & -0.62 & 1.59 & 1.62 & 0.74 \\
\hline $\begin{array}{l}\text { It allows me to share what I usually do at the workplace } \\
\text { with my peers }\end{array}$ & -0.25 & 1.44 & 1.50 & 1.60 \\
\hline $\begin{array}{l}\text { It allows me to share what I usually do at the workplace } \\
\text { with my teacher }\end{array}$ & -0.12 & 1.45 & 1.25 & 1.67 \\
\hline It allows me to better learn & 0.62 & 1.71 & 1.75 & 1.28 \\
\hline $\begin{array}{l}\text { It allows me to make a link between what happens } \\
\text { at the workplace and what they teach at school }\end{array}$ & 1.19 & 1.60 & 2.5 & 0.53 \\
\hline
\end{tabular}

\footnotetext{
* Only valid cases are counted
}

\section{Discussion}

For apprentices, who are generally in their late teens, all the devices investigated appeared easy to use, especially tools such as smartphones, which teenagers are nowadays very familiar with.

The use of headband cameras appeared a little bit more challenging; note that the device we used was a little bit 
complicated, and that in the meantime, a lot of new models of wearable cameras have been produced, especially for sports and leisure time, which should partly improve the result. Indeed, the most often encountered problem concerned framing, which is an operation not directly linked to the interaction with the software of the device but more with aligning the camera viewpoint with the wearer's line of vision. The MOT, that is the online recipe book and learning journal, was the device which led to the more important reservations, regarding its ease of use and its learnability. Its usefulness, however, was seen as quite positive, especially by the cooks.

The significant differences reported between cooks and car mechanics on the perceived usefulness of headband cameras can have various origins; we suppose that the kind of didactics acted by the teacher in the two contexts might account for part of the difference, since the materials were much more integrated in the learning design of the lesson units in the case of cooks than among car mechanics, which in turn brought a higher involvement and participation by apprentices. Of course this hypothesis has to be investigated further properly. As for the attitude towards technology, the significant difference between the two professions may be investigated by considering the types of procedures usually accomplished at the workplace in the two professions: car mechanics' procedures are certainly less suitable to video-recordings because they can be quite long with few visible changes, whereas cooks' procedures are often shorter, faster evolving and easier to follow. Additionally, car mechanics often use intrusive tools in the garages, make physical effort and change locations more often, which is not so much the case for cooks.

The so-called Anxiety dimension proved low for both professions attesting that the apprentices do not feel apprehensive in using the device at the workplace. This represents a good starting point for the implementation of this tool out of the school context.

By contrast, the significant differences in usefulness found with smartphones between cooks and pastry cooks could be due to the fact, once again, that cooks could really use at school the collected materials, thanks to the involvement of their teacher, whereas the experience remained secluded within the workplace for pastry cooks, thus limiting their representation of possible usefulness. The fact that the larger difference between the two professions was seen in the item alluding to the possibility to connect the two learning places thanks to the device can be seen as argument in favor of this explanation.

In the present contribution we assume that ease of use and usefulness are indicators of acceptance and usability, too: through them, we can show how much and in which way a technology (e.g. mobile devices) will be usable and accepted by learners and implemented in such learning contexts. Considering the peculiarity of the VET system, with its many learning locations, mobile learning tools appear usable to apprentices in various workplaces, as they used them while at work in garages, kitchens and pastry cook laboratories; according to the apprentices, tech devices such as headband cameras or smartphones did not obstruct or slow down their activities in those locations.

In the current study, we chose to measure usability in the large mainly through the TAM and UTAUT model, supported by the close link existing between the concept of usability and acceptance, also in order to guarantee the comparability of data collected in a different period of surveying (Note 4).

Apprentices perceive a positive overall ease of use and we show, through the TAM model, that both devices seem to be easy to use in the three professional contexts in which they were integrated: no significant difference is shown, neither between the two devices in the same field (headband $v s$ smartphone cook users), nor between the different professions with respect to the same device. Learnability items seem to give positive results, as the apprentices did not face hard difficulties in using the device, and they also give us the chance to find the way to adapt the tools and the system - as regards the smartphone particularly - in order to make them more comfortable and feasible. In the light of the UTAUT model, we have the possibility to explore how the apprentices perceive other dimensions, also taking into account a potential or real (in the case of apprentice cooks) use for the school. We have to point out once again that the cooks, unlike the other professions, have the chance to experience the re-utilization of the captured material at school. Integrating the collected material to be used at school is the way to be travelled; the learning journal could be the concrete tool to both collect and reflect - maybe through scaffolding prompts - on personal professional practices.

Our study contributes to reflections - within the framework of VET - on the use of technologies as a means to connect and coordinate different learning locations, which is more and more required to foster a deep and grounded learning. Capturing visual materials through mobile devices on activities experienced at the workplace and using them at school to promote specific learning activities can constitute an effective way to give apprentices the chance to learn and reflect on their own professional background. The work jointly conducted by researchers and teachers in designing and building the learning activities seems to have constituted a promising way to reinforce the link between declarative knowledge (usually promoted at school) and procedural knowledge (usually faced at the workplace). This approach does not only allow explicit connection between the two main 
learning locations (the school and the workplace), but it can also have an impact on the learners' motivation and it can offer above all the opportunity for a comparison among professional realities different from one's own, for example, size (small, medium and large enterprises) and typology (e.g. being a cook in a restaurant, hospital etc.). That is the reason why, in the perspective of the learning journal, the involvement of all the learning locations where the apprentices usually live their professional life is recommended. Concretely, on the one side the apprentice pastry cooks could bring the MOT to school and use the material collected because the teacher elaborated fitting learning scenarios; on the other side the apprentice cooks could show the learning journal to supervisors too, in order to collect feedback. In this way, we could perhaps make concrete the idea of a technology which can offer new opportunities for learning, within and beyond the traditional lessons, highlighting all the experiences the apprentices usually live in their multiple contexts.

\section{Acknowledgements}

This study was carried out in the framework of the Leading House "Technologies for vocational training", funded by the Swiss State Secretariat of Education, Research and Innovation.

\section{References}

Cattaneo, A., Dehler, J., Dillenbourg, P., Bétrancourt, M., \& Gurtner, J-L. (2013), The 'Erfahrraum': A model for exploiting educational technologies in dual vocational systems, submitted.

Chambel, T., Zahn, C., \& Finke, M. (2004), Hypervideo Design and Support for Contextualized Learning, Paper presented at the ICALT '04, Proceedings of the IEEE International Conference on Advanced Learning Technologies, Washington. PMid:15583160

Chambel, T., Zahn, C., \& Finke, M. (2006). Hypervideo and Cognition: Designing Video-Based Hypermedia for Individual Learning and Collaborative Knowledge Building. In E. Alkalifa (Ed.), Cognitively Informed Systems: Utilizing Practical Approaches to Enrich Information Presentation and Transfer, Idea Group Publishing. http://dx.doi.org/10.4018/978-1-59140-842-0.ch002

Davis, F. D. (1989). Perceived usefulness, perceived ease of use, and user acceptance of information technology. MIS Quarterly, 13(3), 319-340. http://dx.doi.org/10.2307/249008

Dillon, A. (2001). User Acceptance of Information Technology. In W. Karwowski (ed). Encyclopedia of Human Factors and Ergonomics. London: Taylor and Francis.

Dix, A., Abowd, G., Beale, R., \& Finlay, J. (1998). The Psychology of Human-Computer Interaction, Lawrence Erlbaum Ass, Hillsdale.

El-Hussein, M. O. M., \& Cronje, J. C. (2010). Defining Mobile Learning in the Higher Education Landscape. Educational Technology \& Society, 13(3), 12-21.

Engeström, Y. (1987). Learning by Expanding. An Activity-theoretical approach to developmental research. Helsinki, Orienta-Konsultit.

Engeström, Y., Engeström, R., \& Kärkkäinen, M. (1995). Polycontextuality and boundary crossing in expert cognition: Learning and problem solving in complex work activities. Learning and Instruction, 5, 319-336. http://dx.doi.org/10.1016/0959-4752(95)00021-6

Eraut, M. (2004). Informal learning in the workplace. Studies in Continuing Education, 26, 247-274. http://dx.doi.org/10.1080/158037042000225245

Eteläpelto, A. (2008). Perspectives, prospects and progress in work-related learning. In S. Billett, C. Harteis, \& A. Eteläpelto (Eds.), Emerging perspectives of workplace learning (pp. 233-247). Rotterdam: Sense Publishers.

Filliettaz, L., de Saint-Georges, I., \& Duc, B. (2008). "Vos mains sont intelligentes": Interactions en formation professionnelle initiale. In Cahiers de la Section des Sciences de l'Éducation (Vol. 117). Genève: Université de Genève.

Guile, D., \& Griffiths, T. (2001). Learning through work experience. Journal of Education and Work, 14, 113-131. http://dx.doi.org/10.1080/13639080020028738

Gurtner, J.-L., Monnard, I., \& Genoud, P. A. (2001). Towards a Multilayer Model of Context and its Impact on Motivation. In S. Volet \& S. Järvelä (Eds.), Motivation in Learning Contexts: Theoretical and methodological implications (pp. 189-208). Amsterdam: Pergamon.

Hartson, H. R. (1998). Human-computer interaction: interdisciplinary roots and trends, The Journal of Systems and Software, 43, 103-118. http://dx.doi.org/10.1016/S0164-1212(98)10026-2 
Hix, D., \& Harstson, H. R. (1993). Developing User Interfaces: Ensuring Usability through Product and Process. Wiley: New York. PMid:8106895

Holden, H., \& Rada, R. (2011). Understanding the Influence of Perceived Usability and Technology Self-Efficacy on Teachers' Technology Acceptance, JRTE, 43(4), 343-367.

Horn, I. S., Nolen, S. B., Ward, C., \& Campbell, S. S. (2008). Developing practices in multiple worlds: The role of identity in learning to teach. Teacher Education Quarterly, 35(3), 61-72.

ISO (1996), ISO 9241-10 Ergonomics Requirements for Office Work with VDTs - Dialogue Principles.

Kicken, W., Brand-Gruwel, S., van Merriënboer, J. J. G., \& Slot, W. (2009). The effects of portfolio-based advice on the development of self-directed learning skills in secondary vocational education. Educational Technology, Research and Development, 57, 439-460. http://dx.doi.org/10.1007/s11423-009-9111-3

Kirschner, P. A. (2002). Can we support CSCL? Educational, social and technological affordances for learning. In P. A. Kirschner (Ed.), Three worlds of CSCL: Can we support CSCL? (pp. 7-47). Heerlen: Open University of The Netherlands.

Kukulska-Hulme, A. (2007). Mobile Usability in Educational Contexts: What have we learnt? International Review of Research in Open and Distance Learning, 8(2), 1-16.

Lai, C.-H., Yang, J.-C., Chen, F.-C., Ho, C.-W., \& Chan, T.-W. (2007). Affordances of mobile technologies for experiential learning: the interplay of technology and pedagogical practices. Journal of Computer Assisted Learning, 23, 326-337. http://dx.doi.org/10.1111/j.1365-2729.2007.00237.x

Lave, J., \& Wenger, E. (1991). Situated Learning. Legitimate Peripheral Participation. New York: Cambridge University Press. http://dx.doi.org/10.1017/CBO9780511815355

Ludvigsen, S., Lund, A., Rasmussen, I., \& Säljö, R. (2011). Learning Across Sites. New tools, infrastructures and practices. New York: Routledge.

Mauroux, L., Dehler Zufferey, J., Jimenez, F., Wehren, R., Cattaneo, A., \& Gurtner, J.-L. (2013). Autorégulation des apprentissages et dossiers de formation en formation professionnelle. In J.-L. Berger, \& F. Büchel (Eds.), L'apprentissage Autorégulé: Perspectives théoriques et recherches empiriques (pp 195-227). Nice: Ovadia.

Nielsen, J. (1993). Usability Engineering. Academic Press, London.

OFS. (2012). Niveau de Formation de la Population Résidante, 2012. Office fédéral de la statistique, Neuchâtel. http://www.bfs.admin.ch/bfs/portal/fr/index/themen/15/01/key/blank/01.html.

Pachler, N. (2009). Research methods in mobile and informal learning: some issues. In G. Vavoula, N. Pachler, \& A. Kukulska-Hulme (Eds.), Researching Mobile Learning. Frameworks, tools and research designs (pp. 1-15). Bern: Peter Lang.

Passey, D. (2010). Mobile learning in school contexts: Can teachers alone make it happen? IEEE Transactions on Learning Technologies, 3(1), 68-81. http://dx.doi.org/10.1109/TLT.2009.47

Renkl, A., Mandl, H., \& Gruber, H. (1996). Inert knowledge: Analyses and remedies. Educational Psychologist, 31, 115-121. http://dx.doi.org/10.1207/s15326985ep3102_3

Resnick, L. B. (1987). Learning in school and out. Educational Researcher, 16, 13-20. http://dx.doi.org/10.2307/1175725

Shackel, B. (1991). Usability: context, framework, definition, design, and evaluation. In: Shackel, B., \& Richardson, S. (Eds.), Human Factors for Informatics Usability. Cambridge University Press: Cambridge.

Shackel, B. (1999). Usability - Context, framework, definition, design and evaluation. Interacting with Computers, 21, 339-346. http://dx.doi.org/10.1016/j.intcom.2009.04.007

Sharples, M. (2009). Methods for evaluating mobile learning. In G.N. Vavoula, N. Pachler and A. Kukulska-Hulme (eds). Researching Mobile Learning: Frameworks, Tools and Research Designs: Oxford, Peter Lang Publishing Group, pp. 17-39.

Sharples, M., Taylor, J., \& Vavoula, G. (2005) Towards a Theory of Mobile Learning. In H. van der Merwe \& T. Brown, Mobile Technology: The Future of Learning in Your Hands, mLearn 2005 Book of Abstracts, $4^{\text {th }}$ World Conference on mLearning, Cape Town, 25-28 October 2005. Cape Town: mLearn 2005.

Sharples, M., Taylor, J., \& Vavoula, G. (2007). A theory of learning for the mobile age. In R. Andrews \& C. Haythornthwaite (Eds.), The SAGE Handbook of e-Learning Research (pp. 221-247). London: Sage. http://dx.doi.org/10.4135/9781848607859.n10 
Sharples, M., Arnedillo-Sànchez, I., Milrad, M., \& Vavoula, G. (2008). Mobile learning. Small devices, big issues. In S. Ludvigsen, N. Balacheff, T. De Jong, A. Lazonder, \& S. Barnes (Eds.), Technology-enhanced Learning: Principles and products. Dordrecht: Springer.

Shneiderman, B. (1992). Designing the User Interface: Strategies for Effective Human-Computer Interaction, Addison-Wesley Publishing Company: USA.

Taylor, A., \& Freeman, S. (2011). 'Made in the trade': youth attitudes toward apprenticeship certification. Journal of Vocational Education \& Training, 63, 345-362. http://dx.doi.org/10.1080/13636820.2011.570455

Tynjälä, P. (2008). Perspectives into learning at the workplace. Educational Research Review, 3, 130-154. http://dx.doi.org/10.1016/j.edurev.2007.12.001

Venkatesh, V., Morris, M. G., Davis, G. B., \& Davis, F. D. (2003). User acceptance of information technology: toward a unified view. MIS quarterly, 27(3), 425-478.

Venkatesh, V., \& Davis, F. (2000). A Theoretical Extension of the Technology Acceptance Model: Four $\begin{array}{lllll}\text { Longitudinal Field } \quad \text { Studies. } & \text { Management }\end{array}$ http://dx.doi.org/10.1287/mnsc.46.2.186.11926

Volet, S., \& Järvelä, S. (Eds.) (2001). Motivation in Learning Contexts. Theoretical Advances and Methodological Implications. Amsterdam: Pergamon. PMid:11204210

VPETA, V. (2002). Vocational and Professional Education and Training Act, http://www.admin.ch/ch/e/rs/c412_10.html

Waycott, J. (2004). The appropriation of PDAs as learning and workplace tools, Ph.D. thesis, The Open University.

Zahn C., Schwan S., \& Barquero, B. (2004). Authoring Hypervideo: Design for Learning and Learning by Design. In R. Bromme \& E. Stahl (Eds.), Writing Hypertext and Learning. Conceptual and Empirical Approaches, Oxford, Pergamon.

\section{Notes}

Note 1. The Dual-T project is led by the Leading House "Technologies for vocational training" and it has four main partners: École Polytechnique Fédérale de Lausanne, Centre for Digital Education (CHILI Lab), coordinator; University of Geneva, Faculté de Psychologie et des Sciences de l'Education, TECFA (Technologies de Formation et d'Apprentissage); University of Fribourg, Education Department; and Swiss Federal Institute for Vocational Education and Training (SFIVET). Each partner, in collaboration with the others, focuses on some specific questions applied to different projects. The study presented here takes place in the collaboration context between SFIVET and the University of Fribourg.

Note 2. Note that for the cooks involved in the experiment reported here, the system only consisted of the Recipe Book; it was set up to be re-used in class as the basis for $a d$ hoc learning scenarios, allowing the teacher to pick a selection of the photos uploaded by the apprentices, for his lesson units. Only the pastry cooks were given the chance at that time to fill in the on-line learning journal. The learning journal is now also implemented for cooks so they now have this additional opportunity to reflect on the pictures-enriched recipes they write.

Note 3. Although the TAM model has an entire scale (six items) dedicated to perceived usefulness, we chose to rather select and integrate into the questionnaire several items from the UTAUT because the TAM scale does not really fit with the situation we are studying here: the mobile devices in our case are not tools to accomplish a task, as is expected within the TAM scale, but tools to be used for capturing real experiences at the workplace. Moreover, by choosing the UTAUT, it was possible to select only those items which have a real link with: (1) the VET system and (2) the use of the device in the learning contexts where they were integrated.

Note 4. Further models could be taken into account, such as the Activity System Tool Appropriation Model (ASTAM), elaborated by Waycott. The ASTAM model is based on the so-called Activity System framework illustrated by Engeström (1987), which is used to analyze the process of tool appropriation, defined as 'the integration of a new technology into the user's activities' (Waycott, 2004, p. 54).

\section{(c) $)$ EY}

This work is licensed under a Creative Commons Attribution 3.0 License. 